\title{
Are immunoglobulin E levels associated with early wheezing? A prospective study in Brazilian infants
}

\author{
N. Lopez*, S. de Barros-Mazon", M. Marluce dos Santos Vilela*, A. Condino Neto*, J.D. Ribeiro*
}

Are immunoglobulin E levels associated with early wheezing?: a prospective study in Brazilian infants. N. Lopez, S. de Barros-Mazon, M. Marluce dos Santos Vilela, A. Condino Neto, J.D. Ribeiro. C) ERS Journals Ltd 2002.

ABSTRACT: The relationship between wheezing or asthma and serum immunoglobulin (Ig)E levels in early life is unclear. The aim of this study was to follow-up the IgE immune response in infants that did, or did not, develop recurrent wheezing during their first year of life.

One-hundred and two randomised term neonates were included, in which IgE levels were quantified in cord blood samples, at 3, 6, 9 and 12 months of age. Specific IgE levels for food and inhalant allergens and the skin-prick test for inhalant allergens were also assessed at 6 and 12 months.

During clinical follow-up, $32(31 \%)$ infants presented with two or more wheezing episodes, while $70(69 \%)$ had no wheezing. Total IgE levels were significantly higher up to 12 months in wheezing infants when compared to nonwheezing group. At 12 months, the specific IgE levels to cow's milk, egg white and mites were higher in infants with recurrent wheezing. There was no influence of family history for atopy on IgE levels. The skin-prick tests were positive in $14 \%$ and $23 \%$ in wheezing infants at 6 and 12 months, respectively.

These results indicate an early allergic sensitisation in wheezing infants, suggesting an altered immunoregulatory $\mathbf{T}$-cell role in immunoglobulin $\mathbf{E}$ production. Eur Respir J 2002; 20: 640-645.
*Dept of Pediatrics and Center for Investigation in Pediatrics, "Dept of Clinical Pathology, State University of Campinas (UNICAMP) Medical School, Campinas, Brazil.

\section{Correspondence: J.D. Ribeiro}

Center for Investigation in Pediatrics

State University of Campinas

(UNICAMP) Medical School

P.O. Box 6111

13083-070

Campinas-SP

Brazil

Fax: 551932898638

E-mail: dirceu@head.fcm.unicamp.br

Keywords: Immunoglobulin E

infants

skin-prick test

wheezing

Received: February 272001

Accepted after revision: March 32002
Recurrent wheezing in infancy is a heterogeneous condition. Some children have transient early wheezing, whereas in others, the respiratory symptoms occurring in early life may be the first manifestation of asthma [1].

Factors affecting wheezing in the early years of life and their relationship to the later development of asthma are currently under investigation. The possibility that immune mechanisms may contribute to the beginning of wheeze has been supported by studies that tend to favour an immunoglobulin (Ig)Emediated hypersensitivity type of mechanism. Some authors suggested a prolonged activation of T-helper (Th)2-like immune response after bronchiolitis [2, 3]. Other authors have found higher total IgE levels in young children that presented with persistent wheezing [4].

Little is known about the longitudinal relationship between the $\operatorname{IgE}$ immune responses and allergic sensitisation in infants with early wheezing. The aim of this study was to evaluate prospectively the development of the immune response mediated by $\operatorname{IgE}$ and its association with allergic sensitization in a group of infants that developed recurrent wheezing during their first year of life.
Material and methods

\section{Patients}

This is a 1-yr prospective study that enrolled healthy term neonates weighting $>2,500 \mathrm{~g}$. Term neonates $(\mathrm{n}=282)$ born from April 1996-May 1997 between 08:00-16:00 h, at the University Hospital were randomly included. Twenty-one cases were excluded because the neonates weighted $<2,500 \mathrm{~g}$. One-hundred and fifty cases were further excluded because the mothers did not give consent to join the study. Thus, 114 children (including three pairs of nonidentical twins) were included in the study.

Regarding the clinical manifestations of atopy, infants were followed up from birth to 12 months of age. During the clinical follow-up, these infants were classified as three groups: I) recurrent wheezing; II) other manifestations of atopy, such as urticaria, or reactions to insect stings; III) asymptomatic group [5]. The children from group II were excluded since they presented no respiratory symptoms, and a total of 102 cases were analysed.

This study was approved by the Medical Ethics Committee of the University Hospital at the State 
University of Campinas Medical School (Brazil) and informed consent was provided by the parents before enrolling the child in the study.

\section{Study design}

All infants were examined by the same physician at 3, 6, 9, and 12 months of age at the University Hospital. The mothers answered a standardised questionnaire about clinical manifestations of their babies, including whether or not they presented with episodes of wheezing, the duration of breast-feeding and when egg white was offered to their infants.

Recurrent wheezing was defined as at least two episodes with good response to a $\beta$-adrenergic agonist inhalation and no evidence of respiratory bacterial infection. The $\beta_{2}$-agonist fenoterol in saline $(0.9 \%)$ was administered by an oxygen nebuliser for 5-10 min. The effects of the $\beta_{2}$-agonist were measured by clinical exam 15 and $30 \mathrm{~min}$ after the inhalation by a decrease in respiratory rate and the absence of wheezing at auscultation. A physician clinically documented the episodes of wheezing during the follow-up, and additional examinations were performed at other intervals when necessary.

A positive family history for atopy was considered whenever parents, siblings or grandparents had one or more atopic disorders (asthma, eczema, rhinitis, food allergy). Maternal atopy was confirmed by a positive skin-prick test or a high total IgE level ( $>180$ international units (IU) $\cdot \mathrm{mL}^{-1}$ ) without helminthic infestation.

Cord blood samples were collected immediately after birth by using standard procedures, which included careful cleansing of the cord and strict puncture of the umbilical vein to avoid maternal contamination. A serum sample was obtained from the newborns and also at 3, 6, 9, 12 months of age for total IgE measurement. At 6 and 9 months, the specific IgE levels to cow's milk, egg white and mites (Dermatophagoides pteronyssinus and D. farinae) were determined. All samples were stored at $-80^{\circ} \mathrm{C}$ until assayed. Furthermore, all infants were investigated for helminthic infestation at 6 and 12 months of age and those with a positive exam were excluded.

\section{Allergy skin-prick test}

The allergy skin-prick test was performed on infants at 6 and 12 months of age with standardised extracts from house dust and mites $(D$. pteronyssinus, $D$. farinae), obtained from Daught Laboratories $\mathbb{R}$ (Allergomed Division, Madrid, Spain). Additional skin-prick tests were performed in the mothers on standardised extracts from moulds, as well as dog and cat epithelia. The tests were done in the absence of antihistaminic treatment. Histamine $\left(10 \mathrm{mg} \cdot \mathrm{mL}^{-1}\right)$ was used as a positive control and diluent saline solution as a negative control. A positive test was considered if, after 15-20 min, half of the sum of the largest diameter and its perpendicular measured $\geqslant 3 \mathrm{~mm}$.

\section{Laboratory methods}

Total IgE was measured using an ultrasensitive enzyme-linked immunoassay, $\mathrm{IM}_{\mathrm{x}}$ total $\mathrm{IgE}$ assay

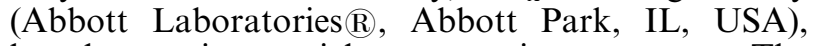
based on microparticle enzyme immunoassay. The results were expressed in IU $\cdot \mathrm{mL}^{-1}\left(1 \mathrm{IU} \cdot \mathrm{mL}^{-1}=2.4 \mu \mathrm{g}\right.$ of $\left.\operatorname{IgE} \cdot \mathrm{L}^{-1}\right)$. The minimum sensitivity of the assay was $0.048 \mathrm{IU} \cdot \mathrm{mL}^{-1}$.

Specific IgE was measured by immunochemiluminometric assay, using the Magic Lite System (Bayer Diagnostics $\mathbb{R}$, Sudbury, UK). The results were expressed in standard units $\left(\mathrm{SU} \cdot \mathrm{mL}^{-1}\right)$ and they were classified into conventional allergy classes $(0-5)$. The high sensitivity protocol was used, with a cut-off value of $0.5 \mathrm{SU} \cdot \mathrm{mL}^{-1}$. A positive test was considered when the values were $>0.5 \mathrm{SU} \cdot \mathrm{mL}^{-1}(0-1$ class $)$.

Total serum IgA was measured by nephelometry (Beckman Instruments ${ }^{\circledR}$ Inc., Galway, Ireland) in cord blood samples. An IgA level $\geqslant 3.23 \mathrm{mg} \cdot \mathrm{dL}^{-1}$ was considered to represent contamination of the cord serum with maternal serum, and the sample was excluded [6].

\section{Statistical methods}

$\operatorname{IgE}$ geometric mean values and standard deviations (SD) were calculated by logarithmic transformation, since IgE values did not show a gaussian distribution. Analysis of variance (ANOVA) with repeated measures was used to analyse the IgE levels in wheezing and nonwheezing infants, and the influence of family history of atopy. The Generalised Estimation Equation evaluated the influence of family history for atopy on specific IgE levels. The correlation between specific $\mathrm{IgE}$ and total $\mathrm{IgE}$ levels was analysed using the Pearson correlation coefficient and the concordance with the skin-prick test by the Kappa coefficient. The Wilcoxon rank-sum test was employed to compare the specific IgE levels between wheezing and nonwheezing at 6 and 12 months of age. The Chi-squared test was used to compare the two groups in relation to the positive skin-prick test and specific IgE levels. All statistical analyses were considered significant when p-values were $\leqslant 0.05$.

\section{Results}

One-hundred and two infants were included in this study. There were $54(53 \%)$ males, $61(60 \%)$ Whites and $41(40 \%)$ Blacks. During the follow-up to 12 months of age, $32(31 \%)$ presented with two or more wheezing episodes and $70(69 \%)$ had no symptoms of wheeze or atopy. Three cord blood samples (3\%) were excluded from the analyses because of maternal blood contamination. One sample at 6 months and two samples at 12 months were also excluded due to helminthic infection.

There were 48 infants $(47 \%)$ that had been breastfed for $<6$ months and their mothers started to offer them cow's milk at $\sim 3$ months of age. Twelve infants 


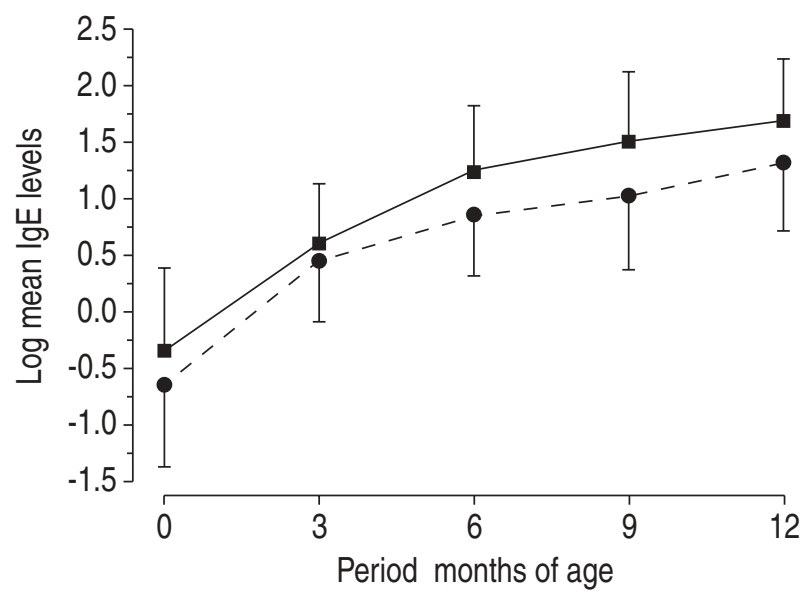

Fig. 1.- Mean total immunoglobulin E (IgE) levels (log values) in infants with recurrent wheezing ( $\boldsymbol{\square})$ and asymptomatic infants (O) during their first year of life. The vertical bars represent the standard deviation. For repeated measures analysis of variance, $\mathrm{p}=0.004$.

$(12 \%)$ received cow's milk since their birth. The egg white was given after 3 months of age to these infants.

Total and specific immunoglobulin $E$ levels and presence of recurrent wheezing

Total serum IgE levels increased according to the age in both group of infants. Mean total IgE levels were higher $(p<0.0004$, ANOVA $)$ in the recurrent wheezing group when compared to the nonwheezing group at all intervals (fig. 1).

At 6 and 12 months, the percentage of infants sensitised against cow's milk, egg white and mite (D. pteronyssinus and D. farinae) was higher in the recurrent wheezing than the nonwheezing group; this was only statistically significant at twelve months (table 1). The specific IgE was also analysed quantitatively to demonstrate the magnitude of the positive class. Higher specific IgE levels to cow's milk $(\mathrm{p}<0.04)$, egg white $(\mathrm{p}<0.02)$, D. pteronyssinus $(\mathrm{p}<0.01)$ and $D$. farinae $(\mathrm{p}<0.05)$ were found in infants with recurrent wheezing (figs. 2 and 3). No relationship

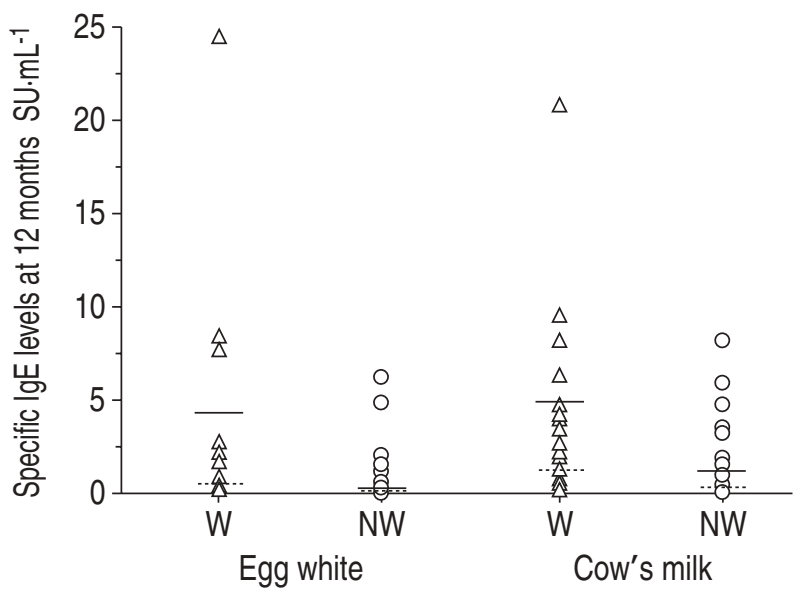

Fig. 2.-Specific immunoglobulin E (IgE) levels to egg white and cow's milk in infants with recurrent wheezing $(\mathrm{W} ; \triangle)$ and asymptomatic infants $(\mathrm{NW} ; \bigcirc)$ at 12 months of age. The extreme values to egg white $\left(\mathrm{W}=89.14 \mathrm{SU} \cdot \mathrm{mL}^{-1}\right)$ and cow's milk $\left(\mathrm{W}=80.93 \mathrm{SU} \cdot \mathrm{mL}^{-1}\right)$ were not plotted. Mean: solid line; Median: dotted line. Wilcoxon rank-sum test for egg white: $\mathrm{p}<0.04$; for cow's milk: $\mathrm{p}<0.02$.

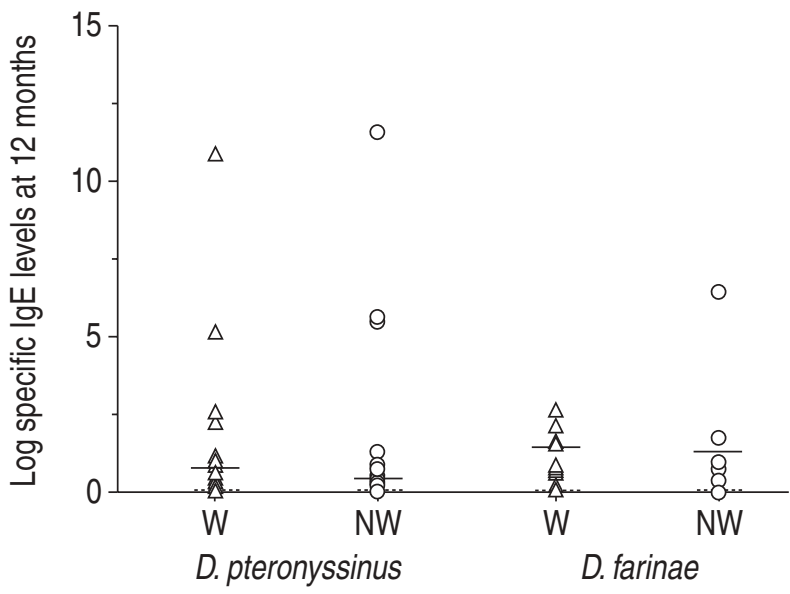

Fig. 3.-Specific immunoglobulin E (IgE) levels to mite in infants with recurrent wheezing $(\mathrm{W} ; \triangle)$ and asymptomatic infants (NW; $\bigcirc)$ at 12 months of age. The extreme values to Dermatophagoides farinae $\left(\mathrm{W}=31.73 \mathrm{SU} \cdot \mathrm{mL}^{-1}\right.$ and $\left.\mathrm{NW}=68.9 \mathrm{SU} \cdot \mathrm{mL}^{-1}\right)$ were not plotted. Mean: solid line; Median: dotted line. Wilcoxon rank-sum test for D. pteronyssinus: $\mathrm{p}<0.01 ;$ D. farinae $\mathrm{p}<0.05$.

Table 1.-Number of infants with positive specific immunoglobulin E (lgE) levels to egg white, cow's milk, Dermatophagoides pteronyssinus and $D$. farinae at 6 and 12 months of age

\begin{tabular}{|c|c|c|c|c|c|c|}
\hline & \multicolumn{2}{|c|}{6 months } & \multicolumn{4}{|c|}{12 months } \\
\hline & \multirow{2}{*}{$\frac{\mathrm{W}}{\mathrm{n}(\%)}$} & \multirow{2}{*}{$\frac{\mathrm{NW}}{\mathrm{n}(\%)}$} & \multicolumn{2}{|c|}{ W } & \multicolumn{2}{|c|}{ NW } \\
\hline & & & n $(\%)$ & $95 \% \mathrm{CI}$ & n $(\%)$ & $95 \% \mathrm{CI}$ \\
\hline Subjects n & 32 & 68 & 30 & & 62 & \\
\hline \multicolumn{7}{|l|}{ Allogens } \\
\hline Egg white & $12(38)$ & $16(24)$ & $13(43)^{\#}$ & $26-62$ & $10(16)$ & $8-28$ \\
\hline Cow's milk & $11(34)$ & $19(28)$ & $18(60)^{\#}$ & $41-77$ & $21(34)$ & $23-47$ \\
\hline D. pteronyssinus & $7(22)$ & $11(16)$ & $9(30)^{\#}$ & $15-50$ & 7 (11) & $5-23$ \\
\hline D. farinae & $6(19)$ & 13 (19) & $10(33)^{\#}$ & $18-53$ & $6(10)$ & $4-21$ \\
\hline
\end{tabular}

W: wheezing infants; NW: asymptomatic infants; CI: confidence interval. \#: The percentages of positive specific IgE levels were significantly greater for W infants compared with NW infants at 12 months of age. Chi-squared test $p \leqslant 0.05$. 
was observed between total $\mathrm{IgE}$ levels and specific $\operatorname{IgE}$ levels.

\section{Skin-prick test}

A positive skin-prick test for at least one of the inhaled allergens, house dust and dust mites (D. pteronyssinus, D. farinae) was found in 14\% (4 of 29) and 23\% (7 of 30) of wheezing infants at 6 and 12 months, respectively. In the same period, the asymptomatic group presented a lower percentage of infants with positive skin-prick tests, $10 \%$ (7 of 68 ) and 10\% (6 of 58) at 6 and 12 months, respectively, but the difference was not statistically significant. There was no concordance between positive skin-prick test and specific IgE levels to these inhalant allergens (Kappa coefficient $\leqslant 0.40$ ).

\section{Influence of family history for atopy on immunoglobulin $E$ levels and presence of recurrent wheezing}

A positive family history for atopy was present in $53 \%$ (54 of 102) of the infants; $39 \%$ (21 of 54) of these developed recurrent wheezing and a positive maternal atopy was confirmed in $43 \%$ (9 of 21$)$. In the group of infants without clinical manifestations, 61\% (33 of 54) had a positive family history for atopy and $45 \%$ (15 of 33) had a positive maternal atopy. Total IgE levels and specific IgE levels were not influenced by positive family history for atopy in infants with and without recurrent wheezing, even if a maternal history for atopy was analysed separately.

\section{Discussion}

Wheezing infants had higher total IgE levels from birth up to 12 months of age. They were also sensitised to some food (egg white, cow's milk) and inhalant allergens (mites) at 6 and 12 months of age, with higher levels directed against these allergens at 12 months.

After birth, individuals with a genetic predisposition for atopy tend to present faster rises in serum IgE levels [7]. Some authors have found that there is a higher risk for atopic disease when IgE concentrations exceed $10 \mathrm{IU} \cdot \mathrm{mL}^{-1}$ during the first year of life [8]. In a cohort study of allergic and nonallergic children from $1 \mathrm{yr}$ until adolescence, significant differences were observed in IgE levels between the two groups up to 11 yrs of age [9]. In the present study, the mean $\operatorname{IgE}$ levels were significantly higher in infants with recurrent wheezing in all periods between birth and $1 \mathrm{yr}$ of age. Nevertheless, low levels of IgE could not exclude later clinical manifestations of recurrent wheezing, because the concentrations varied considerably in this period of life. Furthermore, the broad overlap between $\operatorname{IgE}$ levels in atopic and nonatopic individuals decreases the clinical meaning of this laboratory measurement $[10,11]$. Thus, the present findings cannot ascertain the development of asthma in these wheezing infants solely by considering total IgE levels.

The exposure to an antigen, and the development of sensitisation may occur early, during late pregnancy. Some authors have documented proliferative responses of cord T-cells to some cow's milk proteins [12] or aeroallergens $[13,14]$. In the present study, high total IgE levels were found in cord blood, suggesting early sensitisation, probably by peptides that can gain access to the foetal circulation from the mother [15]. Other hypotheses to explain high cord blood IgE levels involve environmental factors, including maternal smoking during pregnancy and season of birth. These factors act before birth contributing to the regulation of Th2 cells and IgE production [16].

The development of sensitisation to a specific allergen also varies with age [17]. In a prospective study, specific IgE to egg white and cow's milk was found in infants starting from 3 months of age, and reached a peak prevalence at 8 months of age, while $\operatorname{IgE}$ for inhalants appeared from 2 yrs of age $[18,19]$. In this study, the majority of infants received this food early, and $\mathrm{IgE}$ responses to this food and to mite allergens were observed at the first measurement, at 6 months of age. Although these levels were higher in wheezing infants at 12 months, the statistical analyses performed were not used to evaluate enhanced risk of recurrent wheezing. It remains to be established whether these findings are part of an immune response associated with later development of atopy, or can be only a transient imbalance followed by maturation of the immune system [20]. The evidence that IgE directed against egg white at 12 months of age is a valuable marker for subsequent allergic sensitisation to inhalant allergens $[21,22]$ argues the possibility that the present results could be associated with future atopic disease.

Immediate skin tests are widely used to identify sensitisation to a specific allergen and help in the diagnosis of atopic disease [23, 24]. Skin tests for inhalant allergens may assist in the early diagnosis of asthma in wheezing infants [25]. On the other hand, in children $<3$ yrs of age these tests can be unreliable, with a low positivity not correlating with specific IgE $[26,27]$, but others authors have shown that the skinprick test is reliable with high positive correlation with specific IgE [28, 29]. The present study showed a low number of wheezing infants with a positive test for inhaled allergens and no concordance with specific IgE levels. In addition, positive tests were found in the asymptomatic group. Thus, the limits of the interpretation of this test in infants must be considered. These include the relative hyporeactivity and thinness of infant skin, the low frequency of inhalant-specific $\mathrm{IgE}$ in early infancy, and the frequency of falsepositive tests [23].

A great deal of effort has been invested in identifying early markers that will predict ongoing atopic asthma, but an accurate marker has not yet been found. In the first year of life, even a positive family history for atopy has a low sensitivity to identify who will continue to wheeze $[30,31]$. Although the association between high cord blood IgE levels and positive family history for atopy has been described (especially 
for maternal atopy [31, 32]), in the present study, this association in cord blood was not confirmed. Similar results were found by LILJA et al. [33] in other periods during the first year of life.

Early recognition of asthma in wheezing infants is still a major problem for physicians. The only predictor of severe disease is pre-existing atopic eczema [34]. Although the present authors could not define an atopic asthma marker, the specific immunoglobulin E levels to egg white may assist in diagnosis of atopy $\leqslant 12$ months of age as shown in this and several other studies $[21,22]$. The results demonstrated that wheezing infants can present an immune response mediated by immunoglobulin E, suggesting an immunological imbalance. These alterations might suggest the hypothesis of a common defect in the ontogeny of the immune system involving immunoglobulin E production and early allergic sensitisation. A future followup of this cohort will provide more information regarding association with atopy.

Acknowledgements. The authors thank all collaborators who assisted in this research, especially C.M. Silva for her statistical assistance. The study was supported by Fundação de Amparo a Pesquisa do Estado de São Paulo (FAPESP).

\section{References}

1. Martinez FD, Wright AL, Taussig LM, Holberg CJ, Halonen M, Morgan WJ and the Group Health Medical Associates. Asthma and wheezing in the first six years of life. N Engl J Med 1995; 332: 133-138.

2. Román M, Calhoun WJ, Hinton KL, et al. Respiratory syncytial virus infection in infants is associated with predominant Th-2-like response. Am J Respir Crit Care Med 1997; 156: 190-195.

3. Renzi PM, Turgeon JP, Marcotte JE, et al. Reduced interferon- $\gamma$ production in infants with bronchiolitis and asthma. Am J Respir Crit Care Med 1999; 159: 1417-1422.

4. Clough JB, Keeping KA, Edwards LC, Freeman WM, Warner JA, Warner JO. Can we predict which wheezy infants will continue to wheeze? Am J Respir Crit Care Med 1999; 160: 1473-1480.

5. Lopez N, Barros-Mazon S, Vilela MMS, Silva CM, Ribeiro JD. Genetic and environmental influences on atopic immune response in early life. $J$ Investig Allergol Clin Immunol 1999; 9: 392-398.

6. Kimpen J, Callaert H, Embrechts P, Bosmans E. Influence of sex and gestational age on cord blood IgE. Acta Paediatr Scand 1989; 78: 233-238.

7. Burr ML, Merrett TG, Dunstan FDJ, Maguire MJ. The development of allergy in high-risk children. Clin Exp Allergy 1997; 27: 1247-1253.

8. Orgel HA, Hamburger RN, Bazaral M, et al. Development of IgE and allergy in infancy. J Allergy Clin Immunol 1975; 56: 296-307.

9. Lindberg RE, Arroyave C. Levels of IgE in serum from normal children and allergic children as measured by an enzyme immunoassay. J Allergy Clin Immunol 1986; 78: 614.

10. Saarinen UM, Juntunen K, Kajosaari M, Björkstén F.
Serum immunoglobulin $\mathrm{E}$ in atopic and non-atopic children aged 6 months to 5 years. Acta Paediatr Scand 1982; 71: 489-494.

11. Klink M, Cline MG, Halonen M, Burrows B. Problems in defining normal limits for serum IgE. J Allergy Clin Immunol 1990; 85: 440-444.

12. Szépfalusi Z, Nentwich I, Gerstmayr M, et al. Prenatel allergen contact with milk proteins. Clin Exp Allergy 1997; 27: 28-35.

13. Piccinni M-P, Mecacci F, Sampognaro S, et al. Aeroallergen sensitization can occur during fetal life. Int Arch Allergy Immunol 1993; 102: 301-303.

14. Miles EA, Warner JÁ, Jones AC, Colwell BM, Bryant IN, Warner JO. Peripheral blood mononuclear cell proliferative responses in the first year of life in babies born to allergic parents. Clin Exp Allergy 1996; 26: 780-788.

15. Brown MA, Halonen MJ, Martinez FD. Cutting the cord: is birth already too late for primary prevention of allergy? Clin Exp Allergy 1997; 27: 4-6.

16. Parronchi P, Brugnolo F, Sampognaro S, Maggi E. Genetic and environmental factors contributing to the onset of allergic disorders. Int Arch Allergy Immunol 2000; 121: 2-9.

17. Björkstén B. Risk factors in early childhood for the development of atopic diseases. Allergy 1994; 49: 400407.

18. Hattevig G, Kjellman B, Johansson SGO, Björkstén B. Clinical symptoms and IgE responses to common food proteins in atopic and healthy children. Clinical Allergy 1984; 14: 551-559.

19. Hattevig G, Kjellman B, Björkstén B. Appearance of IgE antibodies to ingested and inhaled allergens during the first 12 years of life in atopic and nonatopic children. Pediatr Allergy Immunol 1993; 4: 182186.

20. Platts-Mills TA, Rakes G, Heymann PW. The relevance of allergen exposure to the development of asthma in childhood. J Allergy Clin Immunol 2000; 105: S503-S508.

21. Nickel R, Kulig M, Forster J, et al. Sensitization to hen's egg at the age of twelve months is predictive for allergic sensitization to common indoor and outdoor allergens at the age of three years. J Allergy Clin Immunol 1997; 99: 613-617.

22. Kulig M, Bergmann R, Klettke U, Wahn V, Tacke U, Wahn U. Natural course of sensitization to food and inhalant allergens during the first 6 years of life. J Allergy Clin Immunol 1999; 103: 1173-1179.

23. Zeiger RS. Atopy in infancy and early childhood: natural history and role of skin testing. J Allergy Clin Immunol 1985; 75: 633-639.

24. Yunginger JW, Ahlstedt S, Eggleston PA, et al. Quantitative IgE antibody assays in allergic diseases. J Allergy Clin Immunol 2000; 105: 1077-1084.

25. Delacourt C, Labbé D, Vassault A, Brunet-Langot D, de Blic J, Scheinmann P. Sensitization to inhalant allergens in wheezing infants is predictive of the development of infantile asthma. Allergy 1994; 49: 843-847.

26. Woolcock AJ. Immediate hypersensitivity: a clinical review. Aust NZ J Med 1976; 6: 158-167.

27. Chipps BE, Talamo RC, Mellitis ED, Valentine MD. Immediate (IgE mediated) skin testing in the diagnosis of allergic disease. Ann Allergy 1978; 41: 211-215.

28. Song CH. Skin sensitization in asthmatic children less 
than 36 months of age. Ann Allergy Asthma Immunol 1997; 79: 273-276.

29. Schuetze G, Storm van's Gravesande K, Sparhold S, Frischer T, Kuehr J. Comparison between serial skin-prick tests and specific serum immunoglobulin E to mite allergens. Pediatr Allergy Immunol 1999; 10: 138-142.

30. Odelram H, Bjorkstén B, Leander E, Kjellman N-IM. Predictors of atopy in newborn babies. Allergy 1995; 50: 585-592.

31. Bergmann RL, Edenharter G, Bergmann KE, et al. Predictability of early atopy by cord blood-IgE and parental history. Clin Exper Allergy 1997; 27: 752-760.

32. Bergman RL, Schulz J, Gunther S, et al. Determinations of cord-blood IgE concentrations in 6,401 German neonates. Allergy 1995; 50: 65-71.

33. Lilja G, Magnusson CGM, Kusoffsky E, Johansson SGO, Oman H. Neonatal IgA and IgE levels among infants with paternal heredity for atopic disease. Allergy 1995; 50: 723-728.

34. Warner JO, Pohunek P, Marguet C, Roche WR, Clough JB. Issues in understanding childhood asthma. J Allergy Clin Immunol 2000; 105: S473-S476. 